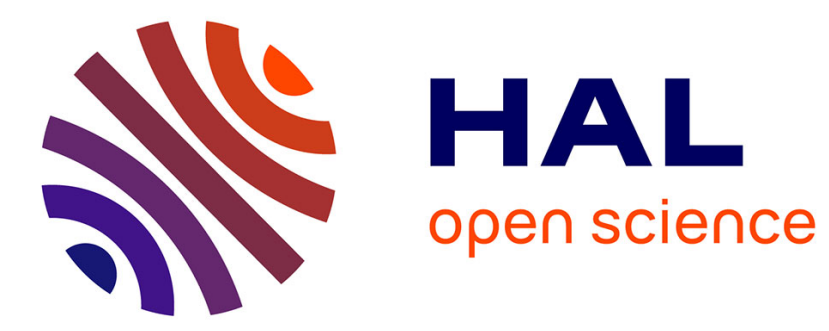

\title{
Pantograph-to-OHL Arc: Conducted Effects in DC Railway Supply System
}

Gabriella Crotti, Antonio Delle Femine, Daniele Gallo, Domenico Giordano, Carmine Landi, Mario Luiso, Andrea Mariscotti, Paolo Emilio Roccato

\section{- To cite this version:}

Gabriella Crotti, Antonio Delle Femine, Daniele Gallo, Domenico Giordano, Carmine Landi, et al.. Pantograph-to-OHL Arc: Conducted Effects in DC Railway Supply System. IEEE Transactions on Instrumentation and Measurement, 2019, 68, 10.1109/TIM.2019.2902805 . hal-02919563

\section{HAL Id: hal-02919563 https://hal.science/hal-02919563}

Submitted on 3 Sep 2020

HAL is a multi-disciplinary open access archive for the deposit and dissemination of scientific research documents, whether they are published or not. The documents may come from teaching and research institutions in France or abroad, or from public or private research centers.
L'archive ouverte pluridisciplinaire HAL, est destinée au dépôt et à la diffusion de documents scientifiques de niveau recherche, publiés ou non, émanant des établissements d'enseignement et de recherche français ou étrangers, des laboratoires publics ou privés. 


\title{
Pantograph-to-OHL Arc: Conducted Effects in DC Railway Supply System
}

\author{
${\text { Gabriella } \text { Crotti }^{(} \text {, Antonio Delle Femine }}^{(}$, Member, IEEE, Daniele Gallo ${ }^{(}$, Member, IEEE, \\ Domenico Giordano ${ }^{\circledR}$, Carmine Landi ${ }^{\circledR}$, Senior Member, IEEE, Mario Luiso ${ }^{\circledR}$, Member, IEEE, \\ Andrea Mariscotti, Senior Member, IEEE, and Paolo Emilio Roccato ${ }^{(1)}$
}

\begin{abstract}
The electrical arc occurring in the sliding contact between the supply contact line and the current collector (pantograph) of an electrical locomotive is a fast transient phenomenon able to degrade progressively the line-to-pantograph contact quality and, consequently, the continuity of operation. In order to increase the energy efficiency of the railway system, an inexpensive solution is constituted by the detection of the arc event by the analysis of voltage and current measurements already available on-board train. An essential activity to reach this objective is to set up a reliable electrical model of the railway system in which the arc events originate. To this end, this paper presents a combination of experimental and simulation analysis for the development of an electrical model of a direct current (dc) $3 \mathrm{kV}$ railway system, which is aimed at better understanding the propagation of conducted effects generated by arc events. First, a laboratory experimental activity is carried out to investigate the electrical dynamic characteristics of the arc in a controlled environment. Then, a model of the dc railway system is derived and validated by using the experimental data collected in a measurement campaign on-board train. Finally, a sensitivity analysis of the main model parameters is carried out.
\end{abstract}

Index Terms-Current measurement, direct current (DC) railway system, electric arc, pantograph-catenary, power system measurements, predictive maintenance, rail transportation, voltage measurement.

\section{INTRODUCTION}

$\mathbf{I}$ $\mathrm{N}$ THE majority of the electric railway systems, the power is transferred from the supply to the traction unit (locomotive or electrotrain) through a sliding contact between the overhead contact line (OHL) and the pantograph. The latter is a servo-actuated current collector placed on the train

Manuscript received November 19, 2018; revised January 21, 2019; accepted February 10, 2019. Date of publication April 16, 2019; date of current version September 13, 2019. The results here presented are developed in the framework of the 16ENG04 MyRailS Project. The latter received funding from the EMPIR programme co-financed by the Participating States and from the European Union's Horizon 2020 Research and Innovation Programme. This work was also supported by the Swiss State Secretariat for Education, Research and Innovation (SERI) under contract number 17.00127. (Corresponding author: Domenico Giordano.)

G. Crotti, D. Giordano, and P. E. Roccato are with the Istituto Nazionale di Ricerca Metrologica (INRIM), 10135 Turin, Italy (e-mail: g.crotti@inrim.it; d.giordano@inrim.it; p.e.roccato@inrim.it).

A. Delle Femine, D. Gallo, C. Landi, and M. Luiso are with Department of Engineering, University of Campania "L. Vanvitelli," 81100 Aversa, Italy (e-mail: antonio.dellefemine@unicampania.it; daniele.gallo@unicampania.it; carmine.landi@unicampania.it; mario.luiso@unicampania.it).

A. Mariscotti is with ASTM, 6830 Chiasso, Switzerland (e-mail: andrea.mariscotti@astm-e.ch).

Color versions of one or more of the figures in this article are available online at http://ieeexplore.ieee.org.

Digital Object Identifier 10.1109/TIM.2019.2902805 roof, which applies and controls the force of the contact strip against the contact line. The large power (up to about $8 \mathrm{MW}$ ) to be transferred from the OHL to the carbon blade of the pantograph through a contact section of a few square millimeters makes the current collection as one of the most critical elements of the electrical railway power chain [1]. The increasing speed of commercial trains associated with the higher and higher power of the traction units requires advanced predictive maintenance techniques to prevent the degradation of the sliding contact and the consequent failure of the overhead contact systems [2]. A lively research activity related to the arc modeling in power systems aims at preventing failures and dysfunctions [3]. More specifically, the attention is directed to the accurate estimation of the induced effects produced by arcing in the railway systems [4], [5], to the analysis of the contact strip degradation with different material composition [6] and to the influence of some parameters affecting the arc phenomena, i.e., the power factor [7], the direct current (dc) polarity [8], etc. The majority of such works addressed alternating current (ac) railway supply systems, neglecting dc systems. The research activity presented in this paper, conversely, is focused on dc systems. It has been developed in the framework of the EMPIR 16ENG04 MyRails research project, which aims at developing the metrological framework to foster the energy efficiency in railway systems. In particular, one of the objectives of this project is to develop a measurement technique to detect the presence of arc phenomena starting from the analysis of voltage and current measurements already available on-board train: the goal is to allow the predictive maintenance based on a continuous monitoring of the arc events, which degrade the overhead contacts and thus decrease the energy efficiency of the whole railway systems, without the need of additional specific measuring devices and so without additional costs. An essential activity to reach this objective is to set up a reliable electrical model of the system in which the arc events originate, which is constituted by the dc railway electrical substations (ESSs), the OHL, the locomotive, and the measuring system. Therefore, this paper is focused on the development of a reliable electrical model aimed at understanding the behavior of voltage and current signals during arc events; the approach adopted, summarized in the following, is a combination of experimental and modeling activity. Section II studies the dynamic electrical characteristics of the arc, by performing laboratory experimental tests in a controlled environment. In Section III, the characteristics 
of the arc behavior are identified, as well as the structure of the circuital model of the railway system, thanks to the information provided by Rete Ferroviaria Italiana (RFI, the Italian railway infrastructure owner). Then, in Section IV, the model is validated by using experimental data collected in a measurement campaign on-board train, performed on a high-speed electrotrain, model ETR 600, and made available by Trenitalia (the largest Italian railway operator). Section V deals with a sensitivity analysis of the main model parameters. Finally, Section VI draws the conclusions.

\section{DyNAMiC V-I ARC ChaRACTERIZATION}

As highlighted in Section I, in the scientific literature a few papers deal with the voltage behavior of an electric arc occurring between the OHL and the pantograph in a dc $3 \mathrm{kV}$ railway system. Therefore, an experimental setup, reproducing a sliding contact similar to that occurring in a railway system, has been realized: the aim is to analyze the dynamic behavior of voltage and current, related to the sliding contact, in order to define the voltage profile of the arc, that is the input of the electrical model developed in Section III.

\section{A. Effects of Pantograph Arcing on Railway Systems}

Pantograph arcing is a common phenomenon in electrified railway systems. It is a source of broadband-conducted and radiated electromagnetic interference (EMI) for the vehicle, as well as for traction power and signaling systems [9]. In addition, the arcing phenomenon produces a localized very high temperature (10 000-13 $000 \mathrm{~K})$, so that corrosion spots of both pantograph and OHL [10] may occur. Therefore, intensive and prolonged arcing phenomena can damage not only the pantograph strip but also the OHL, which can, in turn, accelerate the wear of pantograph of other trains running on the same line section. Moreover, arcing phenomena can produce dumped oscillations on the overhead feeder with frequency content of some kilohertz [11]-[13].

\section{B. Brief Description of the Arc Phenomenon}

An arc is defined as an electric discharge occurring in a conductive ionized gas between two electrodes [14]. The conductive nature of the gas is provided by the plasma between the electrodes, namely a combination of positive ions and free electrons moving in a high-temperature region. As depicted in Fig. 1, the ionized gas between the two electrodes can be divided into three regions: anode region, plasma column, and cathode region; each region is characterized by a different voltage profile. A constant gradient describes the voltage profile in the plasma column, whereas a nonlinear voltage profile is observed for both the anode and cathode regions, where the transition between the solid state of the electrodes and gaseous plasma cloud occurs [14]. For static electrodes, the sum of the voltage drops across the two transition regions only depends on the electrode nature.

A typical voltage-current $(V-I)$ characteristic of a dc arc with a specific length is shown in Fig. 2. At very low current (tens of amperes), a behavior defined by a constant arc power

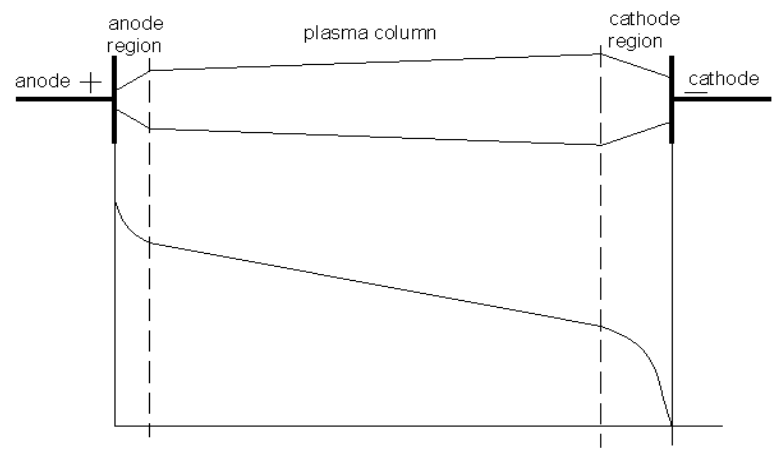

Fig. 1. Voltage drop behavior on the arc length.

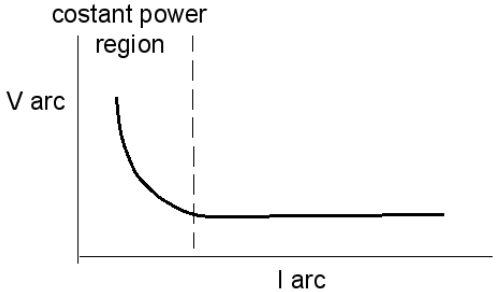

Fig. 2. $\quad V-I$ characteristic of a stationary electrical arc.

TABLE I

EMPIRICAL EXPRESSION OF THE ARC VOLTAGE FOR DIFFERENT GAP VALUES

\begin{tabular}{ccc} 
Electrode gap $[\mathrm{mm}]$ & $V_{\text {arc }}[\mathrm{V}]$ & $V_{\text {arc }}\left(I_{\text {arc }}=100 \mathrm{~A}\right)[\mathrm{V}]$ \\
\hline \hline 1 & $13.04 \cdot I_{\operatorname{arc}}^{0.098}$ & 20.5 \\
5 & $14.13 \cdot I_{\operatorname{arc}}^{0.211}$ & 37.3 \\
10 & $16.68 \cdot I_{\operatorname{arc}}^{0.163}$ & 35.3 \\
20 & $20.11 \cdot I_{\text {arc }}^{0.190}$ & 48.2 \\
\hline
\end{tabular}

law can be observed; for currents higher than a specific threshold, the voltage level does not depend any longer on the current value. Various $V-I$ characteristic curves for dc low-voltage arcs with static electrodes are provided by Paukert [15]: he collected data provided by seven research institutes for current ranging from $100 \mathrm{~A}$ to $100 \mathrm{kA}$ as shown in Table I.

Experimental results presented here have been measured under different dynamic conditions with respect to Paukert's experiments, so that a direct comparison is not immediate. Anyway, compatible results have been obtained, as it will be demonstrated in the following.

\section{Setup of the Arc Generator}

The experimental setup employed in this paper was arranged at the Istituto Nazionale di Ricerca Metrologica (INRIM) in the 1990s for a research project devoted to the analysis of the electromagnetic field at high frequency emitted by the arcs generated between two sliding contacts [4] (see Figs. 3 and 4).

The elements of the sliding contact, namely OHL and pantograph, are emulated by the profile of a $60 \mathrm{~cm}$-diameter copper disk, coupled with the shaft of a dc motor (maximum speed $2 \pi \cdot 50 \mathrm{rad} / \mathrm{s}$, that is $3000 \mathrm{r} / \mathrm{min}$ ) and a real pantograph sliding element. The pantograph is kept against the copper disk edge by means of a weight that, thanks 


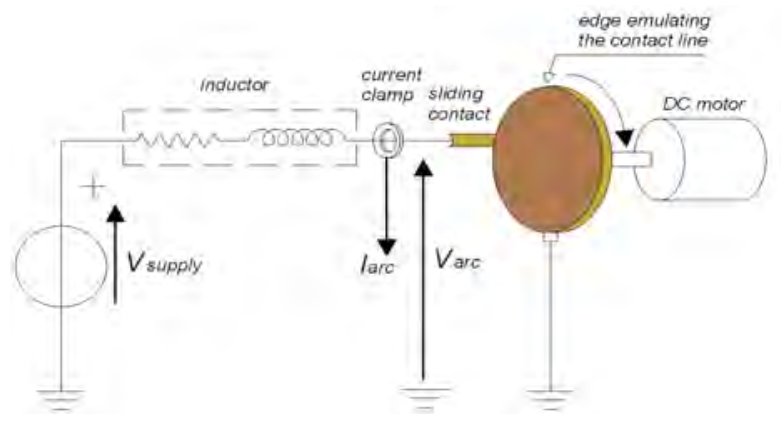

Fig. 3. Simplified circuit of experimental setup.

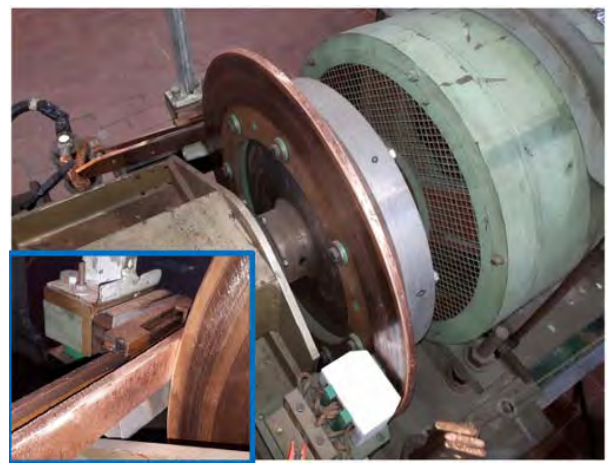

Fig. 4. Experimental setup and detail of contact.

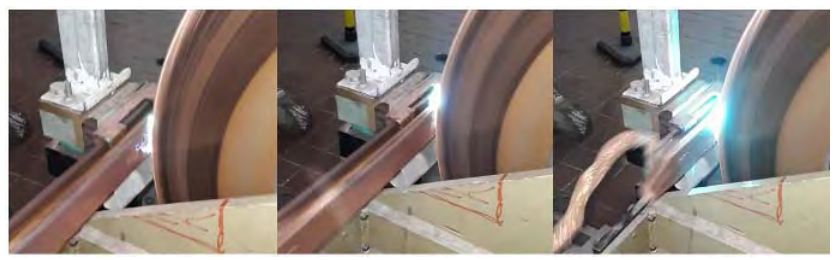

Fig. 5. Arc evolution on the wheel: ignition (left), elongation (middle), and quenching (right).

to a leverage system, provides the correct contact pressure. Moreover, a crank connecting-rod system moved by a compressed air actuator, which allows an alternative horizontal translation of the pantograph, simulates the zig-zag arrangement due to the staggering of the real OHL. Different speeds of the locomotive sliding contact are obtained by varying the motor rotational speed.

The sliding contact is supplied at an almost constant dc voltage. The electrical current flows from the positive pole of the supply system to the rotating disk through a brush system and then, through the sliding contact, to the pantograph, which is connected to the negative pole of the supply. A series of the connected $156 \mu \mathrm{H}$ inductor (resistance of $3.59 \mathrm{~m} \Omega$ ) is used to sustain the arc at the sliding contact.

With the leverage system, it is possible to reduce the contact pressure of the pantograph against the copper disk until it is completely detached and arc injection begins. Then, the distance may be further increased at the point that the arc quenches. An example of arc evolution is shown in Fig. 5.

Different supply conditions and rotation speeds correspond to different quenching distances and arc characteristics. The experimental setup is used to generate arcs with controlled and

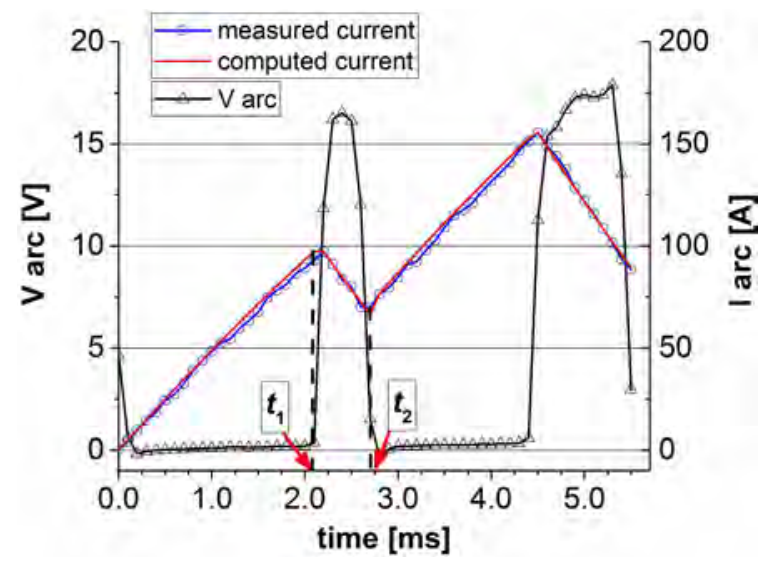

Fig. 6. Comparison between measured and computed current.

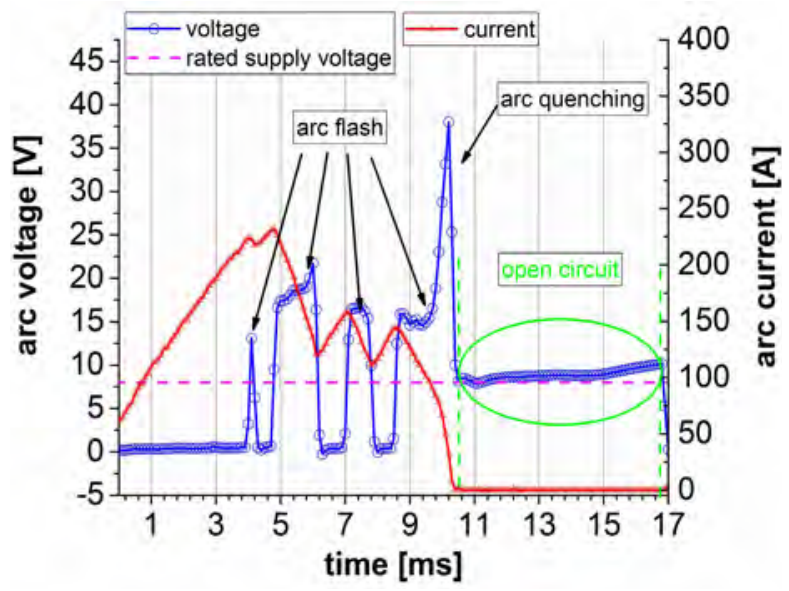

Fig. 7. Arc voltage behavior for different evolution of the arc.

repeatable parameters and under conditions as close as possible to those that can be found in a dc railway supply system.

\section{Experimental Results}

Three electrical quantities have been recorded: the current flowing in the circuit, $I_{\text {arc }}$, the voltage drop across the sliding contact, $V_{\text {arc }}$, and the dc voltage at the power supply, $V_{\mathrm{dc}}$. These quantities have been recorded by means of an acquisition system with sampling frequency of $10 \mathrm{kHz}$. The acquisition system is based on a DEWETRON platform with data acquisition pad-digital multimeter signal conditioners, insulation level up to a root mean square (rms) value of $1.5 \mathrm{kV}$ and bandwidth larger than $25 \mathrm{kHz}$; the current transducers are the Chauvin Arnoux PAC12 clamps, suitable for dc and ac current measurements, with $5 \mathrm{kHz}$ bandwidth [16], [17]. The electrical characteristics of the arc events are shown in Figs. 6 and 7 and they were obtained with a speed rotation of the disk $n=1230 \mathrm{r} / \mathrm{min}$ corresponding to a simulated speed $v$ of the locomotive of $139 \mathrm{~km} / \mathrm{h}$. When a good contact is present between the disk and the pantograph, the time behavior of the current in the circuit follows the typical inductor transient charging [see (1) and Fig. 6] with an exponential increasing of current under constant voltage supply of an $R-L$ circuit. When the arc occurs, a sudden voltage drop, $V_{\text {arc }}$, appears in the circuit and the current time behavior follows the typical 


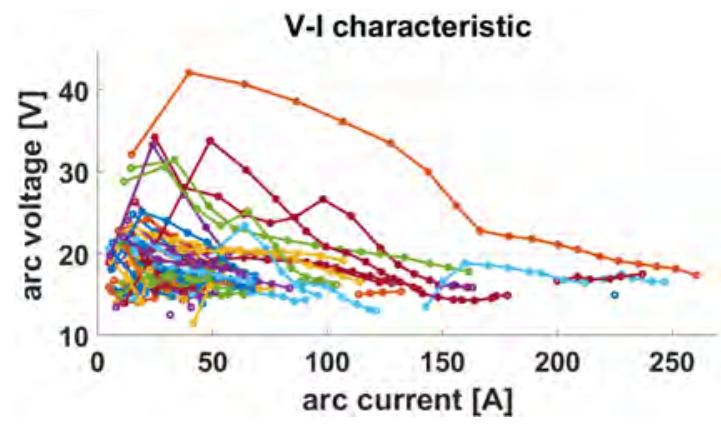

Fig. 8. Collection of volt-ampere characteristic for random arc events.

inductor transient discharge; in other words, the energy stored in the inductor is spent to keep up the arc between the disk and pantograph [see (2) and Fig. 6]. For the sake of brevity, the analytical formulation describing this phenomenon is provided for the first two-time intervals, $0-t_{1}$ and $t_{1}-t_{2}$ highlighted in Fig. 6. The application of Kirchhoff's voltage law to the single-loop circuit shown in Fig. 3 provides the current behavior for the two-time intervals:

$$
\begin{aligned}
i(t)= & \frac{E}{R}\left(1-e^{-t / \tau}\right) \text { for } 0<t<t_{1} \\
i(t)= & \frac{E-V_{\mathrm{arc}}}{R}\left(1-e^{-\left(t-t_{1}\right) / \tau}\right)+I_{0} \cdot e^{-\left(t-t_{1}\right) / \tau} \\
& \text { for } t_{1}<t<t_{2} \quad(\operatorname{arc} \text { event occurring })
\end{aligned}
$$

where $\tau$ is the system-time constant and is defined as $\tau=$ $L / R$, being $R$ the equivalent series resistance that takes into account the stray resistance of the inductor $L$ and the cable connection resistance, $I_{0}$ is the current at time $t=t_{1}$. For the arc events in Fig. 6, a $V_{\text {arc }}$ of about 16-17 V was measured, that is, a value higher than the supply voltage. This is due to the contribution provided by the inductor during its discharge, as demonstrated by the good overlap between computed and measured arc current (see Fig. 6).

From the formula provided in Table I, we can give a rough estimation of the arc length. As an example, the first arc occurrence shown in Fig. $6\left(V_{\text {arcexp }}=16.5 \mathrm{~V}\right)$ has a length of about $1 \mathrm{~mm}$ or less. The onset of the arc events at the sliding contact and their characteristics (duration and length) are random. This fact produces a random current chopping with frequent interruption of the electrical circuit (Fig. 7 provides an example).

It can be seen that with a good electric contact and a nearly zero voltage drop the current increases, but its profile is "chopped" or reverses when arc events are triggered, accompanied by an arc voltage between 15 and $25 \mathrm{~V}$; longer arcs (in terms of length) require higher arc voltage and, consequently, a fast decrease of the current. The arc is broken when the energy stored in the inductor used to sustain the arc is finished (see Fig. 7 at $t=10.5 \mathrm{~ms}$ ).

Several arc events have been collected during each experimental test. Fig. 8 shows some $V-I$ behaviors associated with the arc events with random characteristics (length and duration) recorded during the test carried out with a simulated locomotive speed of $139 \mathrm{~km} / \mathrm{h}$. Since the high number of arc event detected during the test, the current is strongly chopped.
This means that the majority of events occurs at relatively low current $(\sim 70-80 \mathrm{~A})$. The high curve density shown in the left bottom corner of Fig. 8 highlights this phenomenon. A direct comparison between such behavior and the qualitative behavior provided in Fig. 2 is not possible since the electrodes of the setup are moving. Nevertheless, it is evident that for each recorded arc event, two different $V-I$ behaviors can be distinguished, one at higher currents, where the voltage has a lower slope, and one for lower currents, where the voltage slope is steeper. In many cases, at very low current, the voltage tends to fall down: this is the effect of the arc quenching due to a limited energy available in the test circuit.

The experimental setup is expected to have good scaling capabilities with respect to an actual scenario that has higher power and larger inductance. Its main limit is due to the mechanical rigidity of the disk. In fact, the OHLs have a certain amount of elasticity resulting in movement and oscillations under the pressure exerted by the pantograph. This dynamic mechanical behavior is not reproducible with the described system. Anyway, the effect of these oscillations will be taken into account in the following. In real railway systems, a larger supply voltage and inductance can sustain long arc with higher transferred power. On the contrary, such a setup, with an inductance of two orders of magnitude lower than the real one and a lower voltage supply, is not able to sustain long (in terms of time and length) arc events.

However, some general considerations, useful for the comprehension of the real arc event considered in the following, can be deduced. For short-arc event, about $1 \mathrm{~ms}$, the arc voltage is constant during the event, with an amplitude of about $15-20 \mathrm{~V}$, and does not depend on the current flowing in the arc. Moreover, the arc elongation generates a fast increase of the arc voltage (Fig. 7). Such time behavior strongly depends on the mechanical dynamics of the sliding contact, the stochastic path of the arc and the environmental conditions.

\section{Model Description}

A complete circuital model, involving the dc railway supply system, the overhead feeder of the Pisa-Collesalvetti line (Italy) and the input stage of the high-speed electrotrain ETR 600 has been developed, thanks to information provided by RFI and Trenitalia, respectively. The supply voltage, the absorbed/injected current at the pantograph, and the speed of the high-speed train, measured during an approval test performed on the modeled railway line in 2008, have been provided by Trenitalia. Information on the adopted measurement setup was also made available.

\section{A. Test Site}

The line Pisa-Collesalvetti is a $30 \mathrm{~km}$ single track electrified railway line at $3 \mathrm{kV}$ dc with a low gradient; the maximum allowed speed is $150 \mathrm{~km} / \mathrm{h}$. It was chosen as a test line because of its weak supply system compared with the large power of the train under test. The equivalent cross section of the line feeder is $400 \mathrm{~mm}^{2}$ which, related to the large train power, causes a significant voltage drop. These conditions aim at stressing the behavior under weak supply voltage conditions as per EN 50388 standard [18]. 


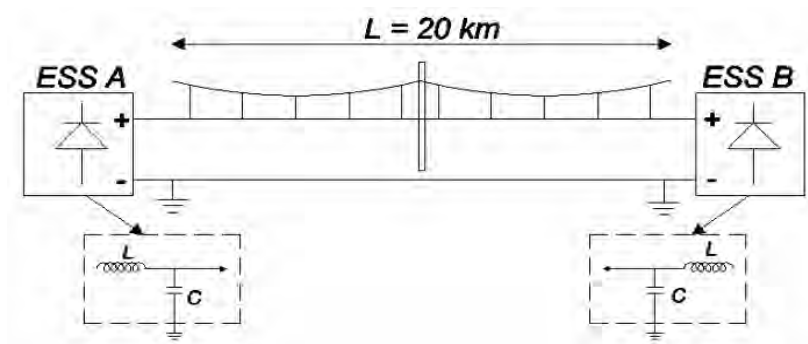

Fig. 9. Scheme of the supply of a dc railway line.

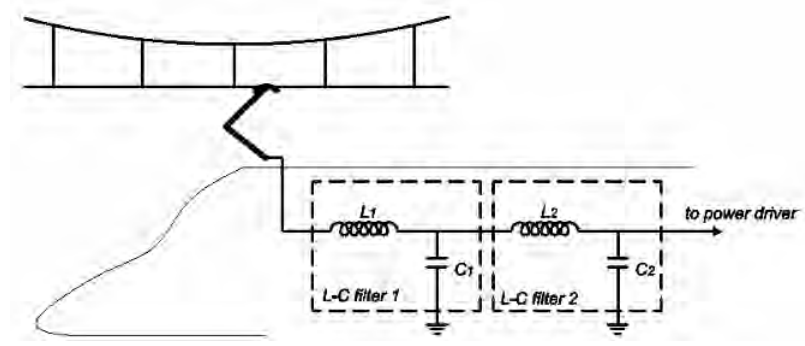

Fig. 10. Scheme of the ETR600 input stage.

The railway line is supplied by two ESSs separated by $20 \mathrm{~km}$. The OHL is made of two overhead contact wires, each of $100 \mathrm{~mm}^{2}$, sustained by a catenary made of two additional $100 \mathrm{~mm}^{2}$ wires. The track has standard $1.435 \mathrm{~m}$ gauge with UNI60 rails. The two ESSs have an installed power of $2 \times 3.6 \mathrm{MW}$ each. The output of the ac/dc converter placed in the substation is connected to an $L-C$ second-order lowpass filter (see Fig. 9) that attenuates the ripple provided by the ac/dc converters. The filter stage is composed of a series connected inductor of $6 \mathrm{mH}$ and a capacitor bank providing $350 \mu \mathrm{F}$ connected to the return of the dc supply (see Fig. 9).

\section{B. Train Under Test}

The electrotrain under test is the high-speed ETR600 class built by Alstom. It can be supplied by the ac $25 \mathrm{kV}-50 \mathrm{~Hz}$ system, the $\mathrm{dc} 3 \mathrm{kV}$ or $1.5 \mathrm{kV}$ systems, or the ac $16.7 \mathrm{~Hz}-15 \mathrm{kV}$ system. The installed power is $5.5 \mathrm{MW}$ and the train can reach a maximum speed of $250 \mathrm{~km} / \mathrm{h}$. The traction architecture is composed of two identical sections, constituted by two three-phase electrical motors. When the train operates under the $25 \mathrm{kV}-50 \mathrm{~Hz}$ system, a $25 \mathrm{kV} / 3 \mathrm{kV}$ transformer (one for each traction section) reduces the supply voltage; the secondary is composed of two windings supplying two ac/dc converters that are parallelly connected on the dc side. The dc bar supplies two dc/ac three-phase converters that feed two electrical motors.

Under a dc supply, the traction system is reconfigured in order to introduce at the input stage two series connected $L-C$ low-pass filters (see Fig. 10).

The first filter has a resonance of $10 \mathrm{~Hz}$ provided by an inductance of $45 \mathrm{mH}$ and a capacitance of $5 \mathrm{mF}$; the second section has a resonance frequency of $100 \mathrm{~Hz}$ with inductance of $0.507 \mathrm{mH}$ and capacitance of $4 \mathrm{mF}$ [19]. The role of this filter is to attenuate the impulsive current absorbed by the dc/ac converters and to reduce harmonic emissions, which

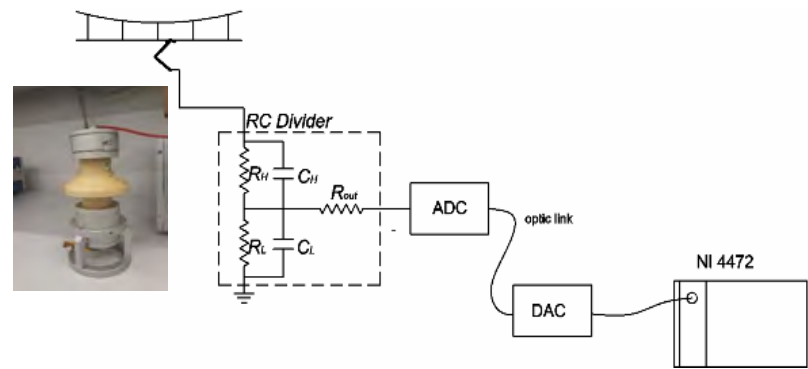

Fig. 11. Pantograph voltage measurement chain.

TABLE II

Voltage Divider Parameters

\begin{tabular}{lr}
\hline \hline$R_{\mathrm{HV}}$ & $6 \mathrm{M} \Omega$ \\
$R_{\mathrm{LV}}$ & $5.9 \mathrm{k} \Omega$ \\
$C_{\mathrm{HV}}$ & $790 \mathrm{pF}$ \\
$C_{\mathrm{LV}}$ & $787 \mathrm{nF}$ \\
$R_{\text {out }}$ & $50 \Omega$ \\
\hline
\end{tabular}

are disturbances also for signaling and telecommunication circuits. For trains with double ac and dc supply modes, the on-board transformer is used also to implement the input filter required for dc systems. When the train is running under the dc supply system, the primary of the transformer is open while the current absorbed by the pantograph flows in the first winding of the secondary and, through a counter-series connection (differential connection), to the second winding of the secondary. Thanks to this configuration, the iron core of the transformer experiences a null magnetic flux and the windings provide their contribution to the total inductance of the first stage of the input filter by means of their leakage flux. Two airinductors series connected provide the remaining inductance necessary to achieve the value of $45 \mathrm{mH}$.

\section{Measurement Setup}

The measurement architecture employed by Trenitalia for these tests was constituted by a resistive-capacitive voltage divider for the measurement of the voltage at the pantograph and a shunt for the total current absorbed by the train. The signals at the output of the two transducers are sent to a National Instrument PXI module through a analog/digital/analog optical link and a data acquisition module (DAQ), as shown in Fig. 11. The values of the divider circuital components are provided in Table II. The bandwidth of the divider is about $20 \mathrm{kHz}$. For what concern the optical link, it has an analog bandwidth of $20 \mathrm{kHz}$.

\section{Overview of the Measurement Data}

The quantities measured at the pantograph are shown in Fig. 12. The voltage drop occurring when the train absorbs a large current highlights the feeder resistance and its limited short circuit power.

The voltage provided by the ESSs can be estimated when the absorbed current is almost zero. In fact, since such measurement campaigns are performed when there is no traffic along the line, an absorption of zero current from the train under test (occurring when train is at standstill or in the 


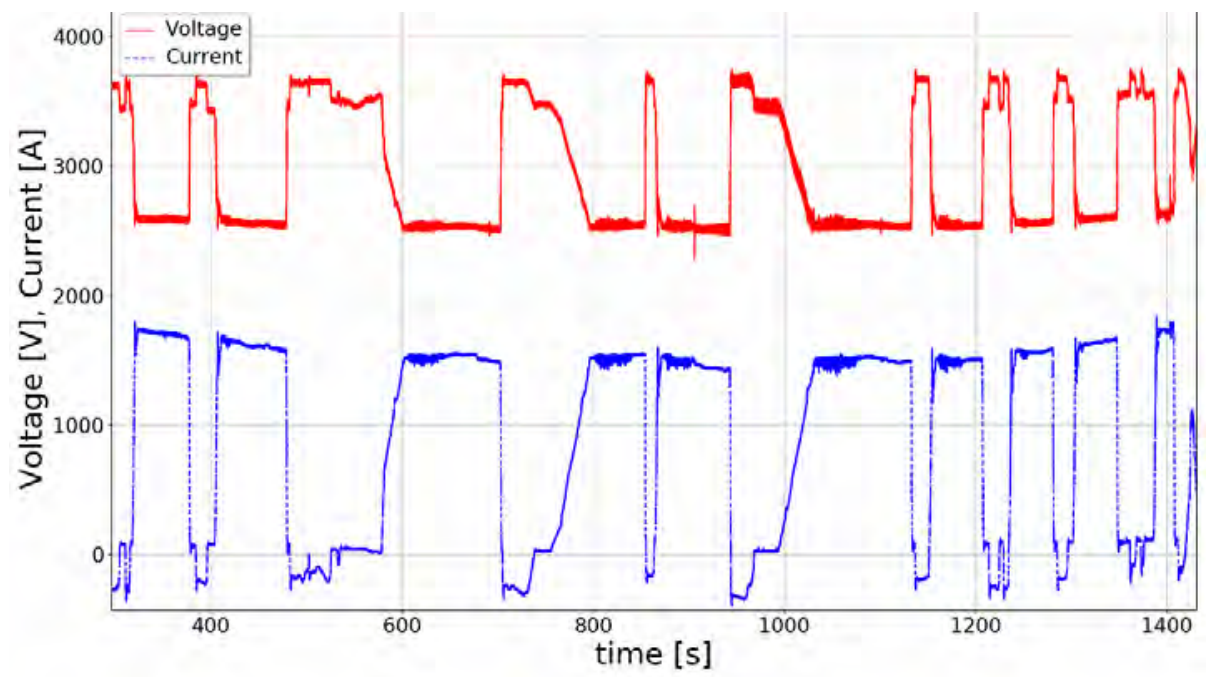

Fig. 12. Time behavior of voltage (red) and current (blue) measured on-board train. Green curve: ac component of the absorbed current.
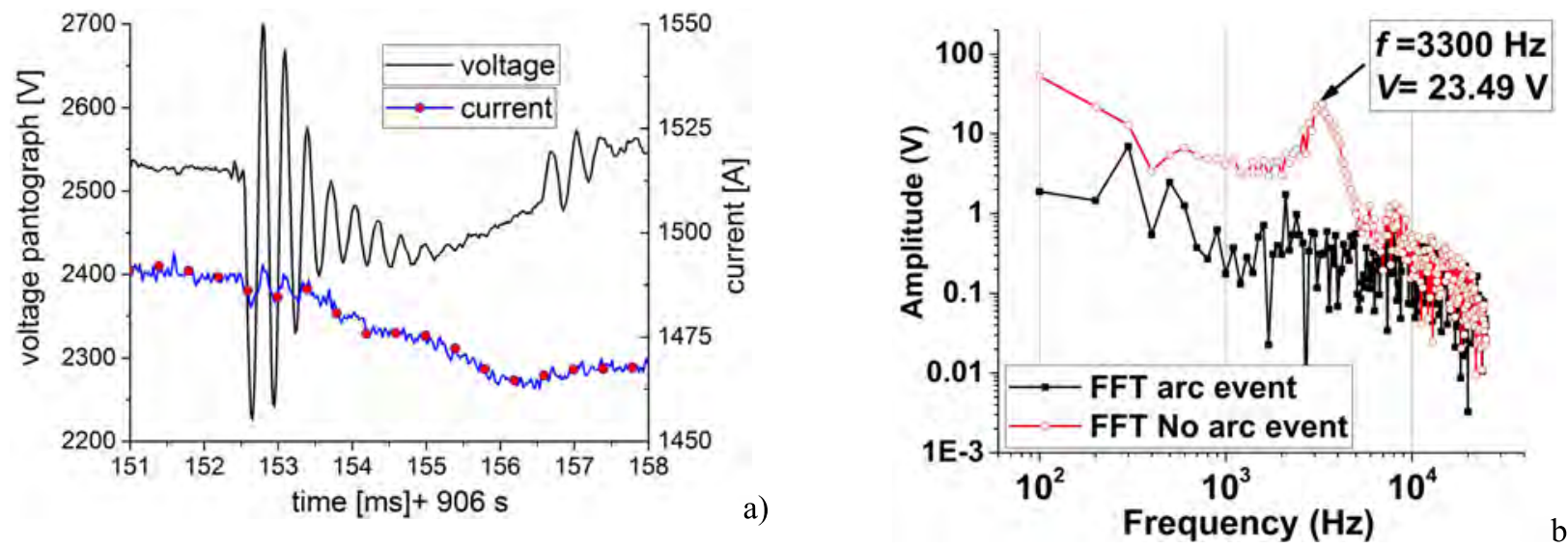

Fig. 13. (a) Time-domain zoom of the pantograph voltage and current during the transient oscillation. (b) Spectrum of the pantograph voltage before (window 1) and during (window 2) the transient oscillation.

coasting phase) allows to estimate the ESS voltage $V_{0}$ that is close to $3.7 \mathrm{kV}$. The maximum voltage drop experienced is about $1200 \mathrm{~V}$ and occurs for an absorbed current of about 1500 A. These considerations allow the estimation of the equivalent resistance of the feeder supplying the train.

An interesting event has been recorded at time $t=906 \mathrm{~s}$ : the voltage transient event and its frequency spectrum are provided in Fig. 13, showing that the transient has a typically dumped oscillation with a frequency of about $3.3 \mathrm{kHz}$. After about $4 \mathrm{~ms}$, a new oscillation of lower amplitude is triggered but disappears immediately.

\section{E. System Electrical Model}

The circuital model, developed in PSPICE, is shown in Fig. 14. The two OHL sections are simulated as lossy distributed-parameter lines [19]. The electrical parameters of the voltage divider and of the traction line are shown in Tables II and III [20].

Since the focus is on the transient events, the only applied voltage is that of the arc event, with the $3 \mathrm{kV}$ dc bias fed by the two substations neglected and replaced by a short circuit. The dc supply voltage amplitude will be added to the computed

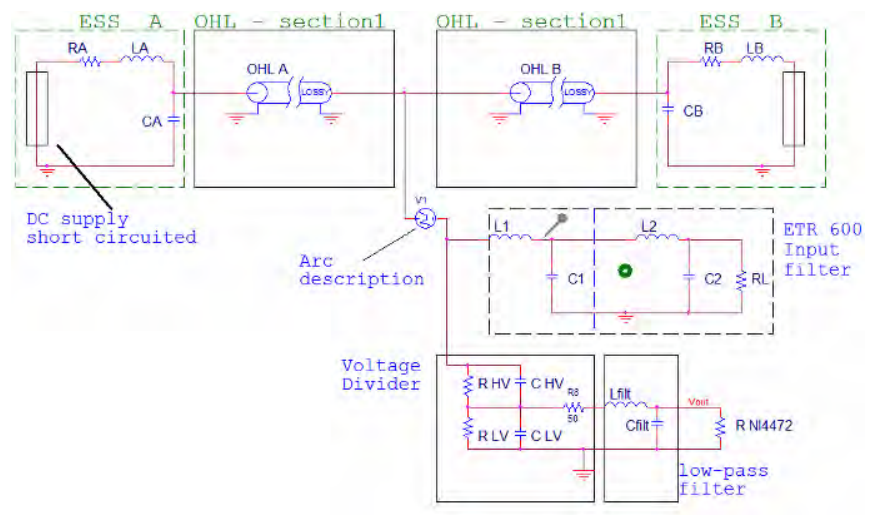

Fig. 14. Circuit model for the analysis of arc conducted effects.

output voltage in order to perform the comparison with the real measurements.

\section{F. Measurement Filter}

The Italian procedure for the evaluation of harmonic distortion of the current and voltage waveforms requires a bandwidth of about $4.3 \mathrm{kHz}$ [21]. The real acquisition system is simulated 
TABLE III

EleCtrical PARAMETERS OF THE TraCtion Line

\begin{tabular}{rr}
\hline \hline$L_{\mathrm{HOL}}$ & $0.57 \mu \mathrm{H} / \mathrm{m}$ \\
$R_{\mathrm{OHL}-\mathrm{DC}}$ & $0.17 \mathrm{~m} \Omega / \mathrm{m}$ \\
$C_{\mathrm{HOL}}$ & $20 \mathrm{pF} / \mathrm{m}$ \\
$G_{\mathrm{HOL}}$ & $100 \mathrm{MS}$ \\
\hline
\end{tabular}

by introducing a second-order filter. After several computations and comparisons with the actual voltage waveform, the resonance frequency of the filter has been fixed equal to the observed oscillation frequency of the damped voltage transient, i.e., $3.3 \mathrm{kHz}$. In order to improve the fit between computation and measurement, the overshoot produced by the filter has been emphasized. The inductance of the filter is fixed to $L_{\text {filt }}=20 \mathrm{mH}$. As it is shown later, this quantity strongly affects the behavior of the computed voltage at the output of the measurement chain.

\section{G. Model of the Arc Event}

Following the conclusions of Section II, the arc event, which is the input to the model, has been introduced as an impulsive voltage source connected between the OHL and the input stage of the train. Different shapes of this voltage source have been considered in order to identify the transient arc event that best fits the measured data.

As detected experimentally in Section II, the arc ignition voltage is about $15 / 20 \mathrm{~V}$. With the increase of the arc length, whose amplitude and duration depend on the dynamics of the sliding contact, the arc voltage increases too (see Fig. 7). In the experimental case, the increase of the arc voltage, as a consequence of the arc elongation, is the only possible phenomenon, thanks to the energy stored in the series inductance. When the inductance is completely discharged, we observe the arc quenching. In a real railway system, the system supply circuit at $3 \mathrm{kV}$ is generally able to feed the arc allowing the dynamic evolution of the sliding contact without arc quenching. According to these considerations, the estimated arc voltage that provides the best fit between measurement and simulation (i.e., the optimized arc voltage profile) has the time behavior approximately reproducing the arc voltage profile detected in the experiment described in Section II (see Fig. 15).

After a first fast detachment of the pantograph from the OHL, described by the fast increase of the arc voltage, a slower mechanical oscillation of the pantograph occurs. This oscillation is roughly reproduced by the linear increase and successive decrease of the arc voltage shown in Fig. 16, where we see the complete time behavior of the arc voltage. The overall duration of the event is $4 \mathrm{~ms}$. After a fast arc voltage increase, $230 \mathrm{~V}$ in $100 \mu \mathrm{s}$, and a fast decrease, $180 \mathrm{~V}$ in $100 \mu \mathrm{s}$, a slower oscillation occurs.

\section{Model Validation}

Two different arc voltage profiles have been applied, as input, to the proposed model: a rectangular pulse and the optimized arc profile, as shown in Fig. 17.

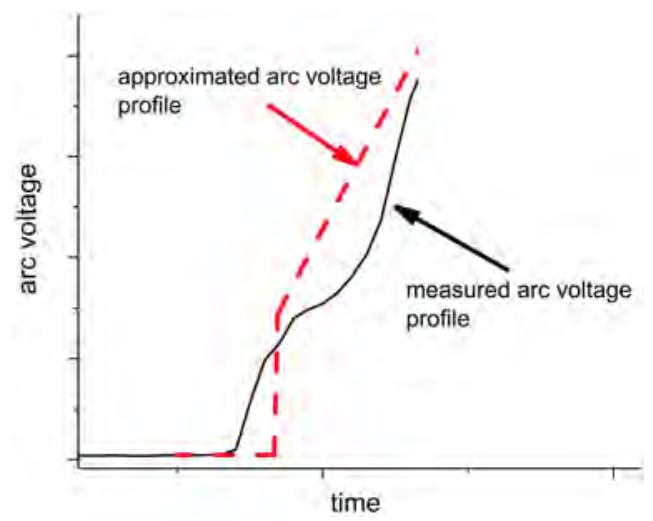

Fig. 15. Time behavior, in the initial part of the event measured and approximated.

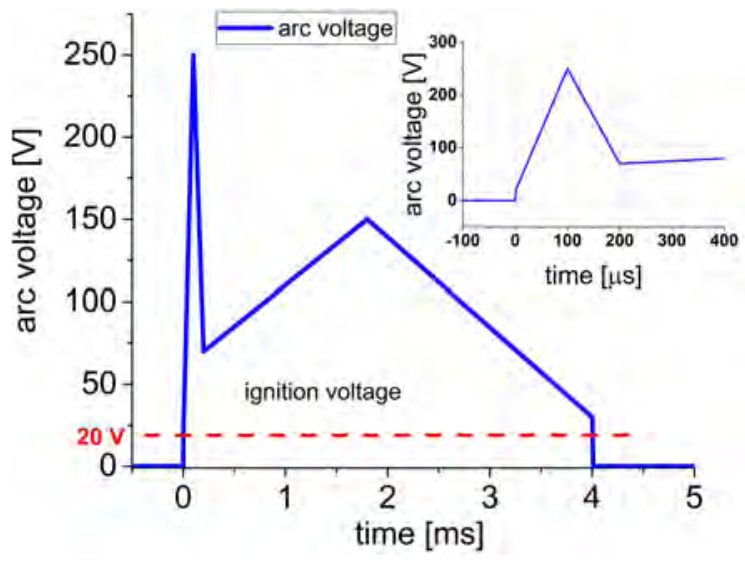

Fig. 16. Time behavior of the simulated arc voltage.

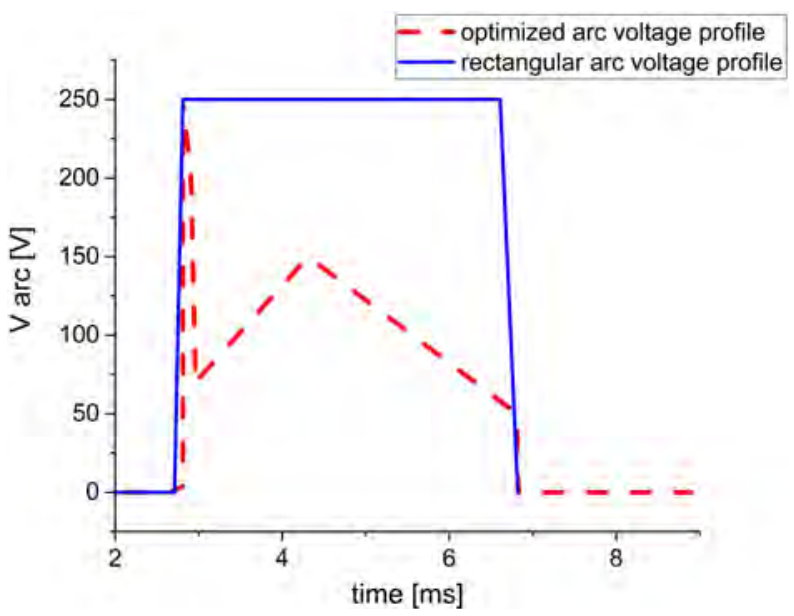

Fig. 17. Time behavior of the rectangular and the simulated arc voltage at the pantograph.

Fig. 18 compares the simulated behavior obtained with the optimized arc voltage profile and the rectangular one with the measured oscillation.

The rectangular pulse is the worst arc voltage candidate not only because it does not account the variability of the arc resistance when length changes (see Fig. 17) but also because the resulting pantograph voltage is quite different from the experimental one, as shown in Fig. 18. In the circuit model, the arc is represented with a generator, whose resistance is, 


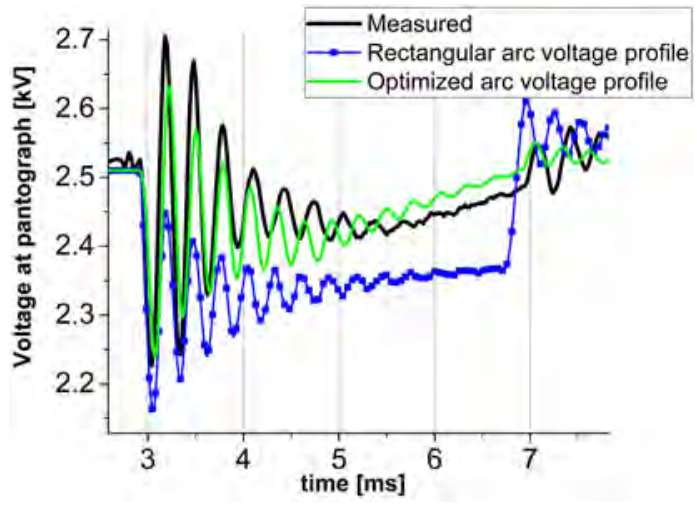

Fig. 18. Comparison between voltages measured at the pantograph and simulated one.

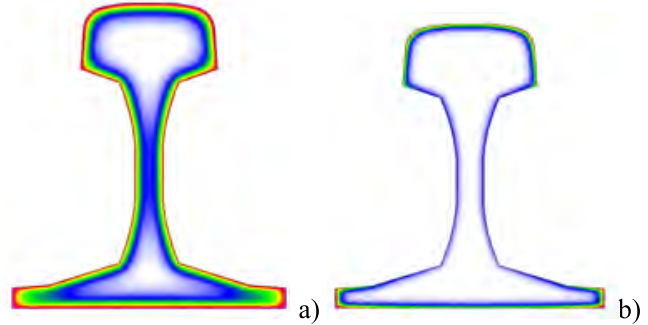

Fig. 19. Map of the magnetic induction strength for (a) $50-\mathrm{Hz}$ injected current signal and (b) $2-\mathrm{kHz}$ current signal.

in general, negligible as shown in [18, Fig. 14], where values of $10-100 \mathrm{~m} \Omega$ are reported.

In our case, the observed values are of the same order (see Table I where the estimated resistance values range between 0.2 and $0.5 \Omega$ ).

\section{Sensitivity}

A sensitivity analysis was carried out for the OHL resistance $\left(R_{\mathrm{OHL}-\mathrm{dc}}\right)$ and for $L_{\text {filt }}$. Considering the relatively high-frequency energy content of the analyzed phenomena, the skin effect can considerably increase the OHL resistance. In order to estimate these effects, an accurate finite-element method (FEM) simulation was carried out for the running rails as shown in Fig. 19. The same figure also provides a visible qualitative impact of the skin effect by comparing side by side the magnetic induction field in the material at two different frequencies of the applied current: $50 \mathrm{~Hz}$ and $2 \mathrm{kHz}$. Results are in substantial agreement with those in [22]. The resulting skin effect makes the longitudinal resistance much larger for the frequency values characterizing the arc phenomena.

The effect of the traction line resistance on the estimated voltage waveform at the output of the measuring chain is provided in Fig. 20(a), where the estimated pantograph voltage was calculated for the following values of $R_{\mathrm{OHL}-\mathrm{dc}}: 0.17,1$, and $3 \mathrm{~m} \Omega / \mathrm{m}$.

The effect on the simulated measurement chain output of the filter inductance $L_{\text {filt }}$ was calculated for 10,20 , and $30 \mathrm{mH}$. The results are provided in Fig. 20(b). In particular, for lower values of the filter inductance, the damping effect increases. In addition, the oscillation frequency is slightly reduced for higher inductance values.

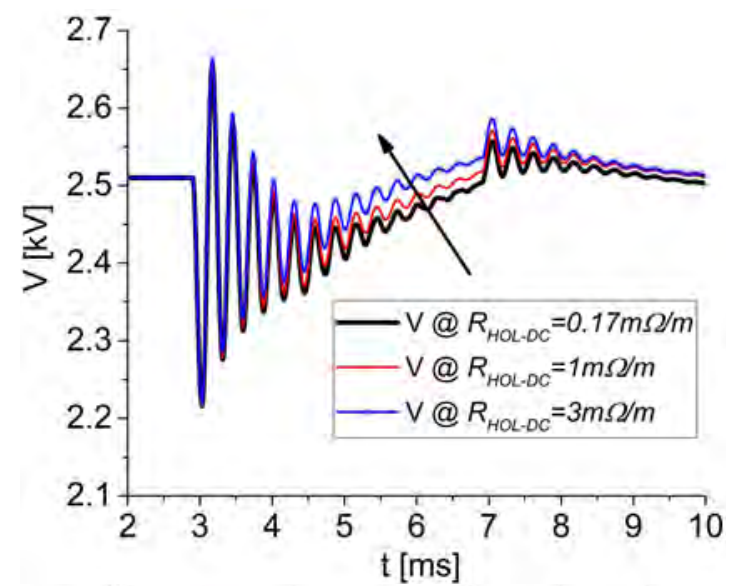

(a)

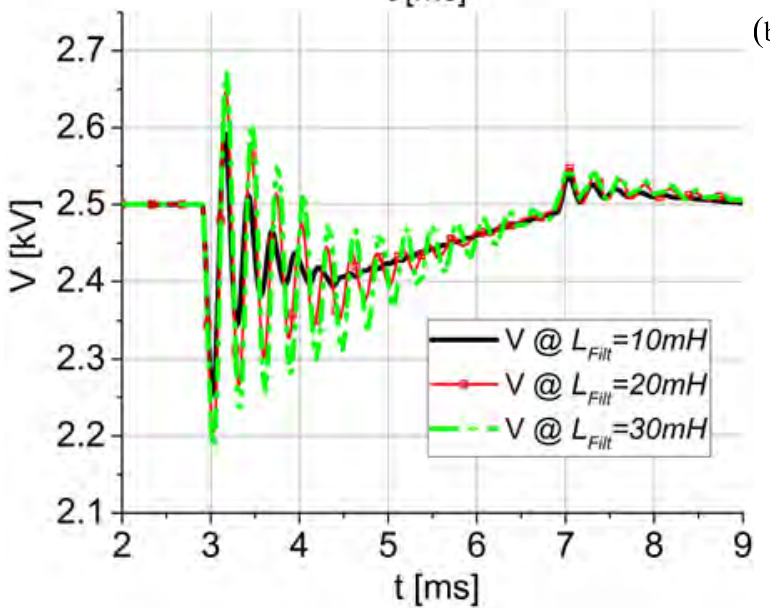

(b)

Fig. 20. Effect of the OHL resistance ROHL-dc on the estimated voltage at the output of the measurement chain. Effect of (a) resistance and (b) inductance.

\section{CONCLUSION}

A tool for the estimation of the conducted effects produced by pantograph-to-OHL arc events on the dc railway system has been developed and validated.

The tool includes a complete model of the measurement chain which allows its testing with the on-board collected electrical data.

Thanks to the knowledge on the arc phenomena got from the laboratory experiments and the available measurements of the voltage and current at the pantograph, the arc voltage profile associated with a real detected event has been deduced and provided as input to the model. The comparison between pantograph voltage simulation and on-board recorded measurements is found in good agreement, whereas it is unsatisfactory in the case of simplified rectangular arc voltage profile of the same amplitude.

The analysis of the overall line resistance $(\mathrm{OHL}+$ track) variation on the model output shows a limited effect. Being complex the estimate of the skin effect in transient conditions, this result provides robustness to the model.

The tool will be used in the study of conducted arc effects along the supply line, for different position of the train and different locomotives. It will then play an important role in the development of arc event detectors that exploit the on-board voltage-current measuring systems generally used for power 
and energy measurements. Moreover, it will be used to investigate the accuracy of the devices (measurement systems and identification algorithm) for the arc event detection.

\section{ACKNOWLEDGMENT}

The authors wish to thank Prof. M. Chiampi for his contribution to the estimation of the skin effect in the rail tracks.

\section{REFERENCES}

[1] S. Midya, "Conducted and radiated electromagnetic interference in modern electrified railways with emphasis on pantograph arcing," M.S. thesis, Dept. Electromagn. Eng., KTH Roy. Inst. Technol., Stockholm, Sweden, 2009.

[2] O. Bruno, A. Landi, M. Papi, and L. Sani, "Phototube sensor for monitoring the quality of current collection on overhead electrified railway," Proc. Inst. Mech. Eng., F, J. Rail Rapid Transit, vol. 215, no. 3, pp. 231-241, May 2001.

[3] J. Li, D. W. P. Thomas, M. Sumner, E. Christopher, and Y. Cao, "Series arc fault studies and modeling for a DC distribution system," in Proc. IEEE PES Asia-Pacific Power Energy Eng. Conf. (APPEEC), Dec. 2013, pp. 1-6.

[4] M. Borsero, G. Farina, and G. Vizio, "RF disturbance field produced by the panthograph-catenary contact," in Proc. Int. Symp. Electromag. Compat., Sep. 1998, pp. 46-51

[5] B. Tellini, M. Macucci, R. Giannetti, and G. A. Antonacci, "Conducted and radiated interference measurements in the line-pantograph system," IEEE Trans. Instrum. Meas., vol. 50, no. 6, pp. 1661-1664, Dec. 2001.

[6] W. Wang et al., "Experimental study of electrical characteristics on pantograph arcing," in Proc. 1st Int. Conf. Elect. Power Equip.-Switching Technol., Oct. 2011, pp. 602-607.

[7] K. Peng and G. Gao, "The influence of power factor and traction current on pantograph-catenary arc energy," in Proc. IEEE Int. Conf. High Voltage Eng. Appl. (ICHVE), Sep. 2016, pp. 1-4.

[8] S. Midya, D. Bormann, T. Schutte, and R. Thottappillil, "Pantograph arcing in electrified railways-Mechanism and influence of various parameters-Part II: With AC traction power supply," IEEE Trans. Power Del., vol. 24, no. 4, pp. 1940-1950, Oct. 2009.

[9] Y. I. Zharkov, Y. G. Semenov, D. V. Kolosov, and J. Otýpka, "The principals of operation of the automated current collection diagnostic system for electrified railways," in Proc. 16th Int. Sci. Conf. Elect. Power Eng. (EPE), May 2015, pp. 760-763.

[10] G. Gao, J. Hao, W. Wei, H. Hu, G. Zhu, and G. Wu, "Dynamics of pantograph-catenary arc during the pantograph lowering process," IEEE Trans. Plasma Sci., vol. 44, no. 11, pp. 2715-2723, Nov. 2016.

[11] G. Crotti et al., "Pantograph-to-OHL arc: Conducted effects in DC railway supply system," in Proc. IEEE 9th Int. Workshop Appl. Meas. Power Syst. (AMPS), Bologna, Italy, Sep. 2018, pp. 1-6.

[12] F. A. Delle, D. Gallo, D. Giordano, C. Landi, M. Luiso, and D. Signorino, "Synchronized measurement system for railway application," J. Phys., Conf. Ser., vols. 1065, no. 5, 2018, Art. no. 052040.

[13] G. Crotti, D. Giordano, A. D. Ferninc, D. Gallo, C. Landi, and M. Luiso, "A testbed for static and dynamic characterization of DC voltage and current transducers," in Proc. IEEE 9th Int. Workshop Appl. Meas. Power Syst. (AMPS), Bologna, Italy, Sep. 2018, pp. 1-6.

[14] R. F. Ammerman and P. K. Sen, "Modeling high-current electrical arcs: A volt-ampere characteristic perspective for AC and DC systems," in Proc. 39th North Amer. Power Symp., Sep./Oct. 2007, pp. 58-62.

[15] J. Paukert, "The arc voltage and the resistance of LV fault arcs," in Proc. Int. Symp. Switching Arc Phenomena, Lodz, Poland, 1993, pp. 49-51.

[16] A. Cataliotti et al., "Compensation of nonlinearity of voltage and current instrument transformers," IEEE Trans. Instrum. Meas., to be published. doi: 10.1109/TIM.2018.2880060.

[17] G. Crotti, A. D. Femine, D. Gallo, D. Giordano, C. Landi, and M. Luiso, "Measurement of the absolute phase error of digitizers," IEEE Trans. Instrum. Meas., to be published. doi: 10.1109/TIM.2018.2888919.

[18] Railway Applications. Power Supply and Rolling Stock. Technical Criteria for the Coordination Between Power Supply (Substation) and Rolling Stock to Achieve Interoperability, document EN50388, 2012.

[19] "Elettrotreno ad assetto variabile ETR 600-Manualer di manutenzione di II livello, Equipaggiamento elettronico-Descrizione manutenzione dei circuiti AT," Tech. Rep., ETR600 MR2 04-1 10, May 2013.

[20] A. Mariscotti and P. Pozzobon, "Synthesis of line impedance expressions for railway traction systems," IEEE Trans. Veh. Technol., vol. 52, no. 2, pp. 420-430, Mar. 2003.
[21] Maschera FS 96 Specifica Tecnica Di Prova Per La Verifica Delle Componenti Della Corrente Di Trazione, document NÂ370582, 1997.

[22] F. Filippone, A. Mariscotti, and P. Pozzobon, "The internal impedance of traction rails for DC railways in the $1-100 \mathrm{kHz}$ frequency range," IEEE Trans. Instrum. Meas., vol. 55, no. 5, Oct. 2006, pp. 1616-1619.

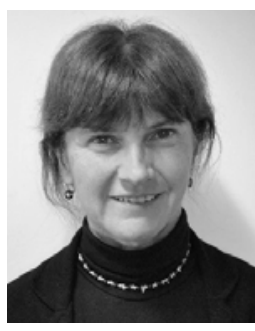

Gabriella Crotti received the Laurea degree in physics from the University of Torino, Turin, Italy, in 1986.

Since 1986, she has been with the Istituto Nazionale di Ricerca Metrologica (INRIM), Turin, Italy, where she is currently the Director Technologist of the Quality of Life Division, Energy and Enviroment Group of the Metrology. Her current research interests include the development and characterization of references and techniques for voltage and current measurements in high and medium voltage grids and on the traceability of electric and magnetic field measurements at low and intermediate-frequency.

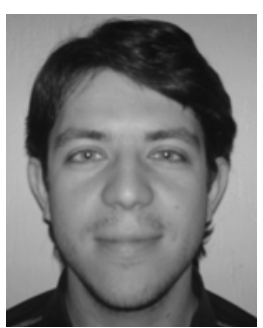

Antonio Delle Femine (S'08-M'19) was born in Caserta, Italy, in 1980. He received the M.Sc. degree (summa cum laude) in electronic engineering and the $\mathrm{Ph} . \mathrm{D}$. degree in electrical energy conversion from the University of Campania "Luigi Vanvitelli," Aversa, Italy, in 2005 and 2008, respectively.

From 2008 to 2017, he was a freelancer with many national and international companies. He was a Software Engineer, a Senior Embedded Firmware Engineer, a Hardware Engineer, and the Project Manager. He was involved in the design of many products for both industrial and consumer electronics, fleet monitoring systems, thermal printers, electronic scales and cash registers, distributed monitoring systems for photovoltaic plants, Hi-Fi radios and home appliances, automatic end-ofline testing systems, augmented reality devices, and radioactivity measurement instrumentation (in collaboration with national institute of nuclear physics, INFN). In 2018, he joined the University of Campania "Luigi Vanvitelli" as a Researcher. His current research interests include the power measurement theory, design, implementation and characterization of digital-measurement instrumentation and of automatic measurement systems, radioactivity measurements.

Dr. Femine is a Member of the IEEE Instrumentation and Measurement Society.

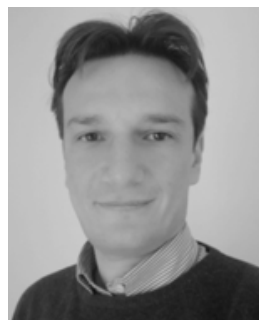

Daniele Gallo (S'00-M'04) was born in 1974. He received the Laurea degree in electronic engineering and the Ph.D. degree in electrical energy conversion from the University of Campania "Luigi Vanvitelli," Aversa, Italy, in 1999 and 2003, respectively.

$\mathrm{He}$ is currently an Associate Professor with the University of Campania "Luigi Vanvitelli." He has authored or co-authored more than 130 papers published in books, international scientific journals, and conference proceedings. His current research interests include design, implementation, and characterization of measurement systems for electrical power system, power quality issues, power and energy measurement in nonsinusoidal conditions, design and implementation of smart meter for smart grid application, and electrical transducer characterization.

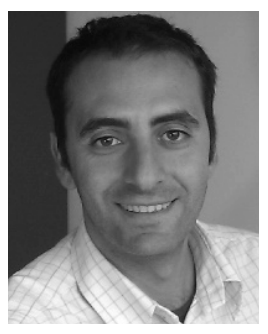

Domenico Giordano received the Ph.D. degree in electrical engineering from the Politecnico di Torino, Turin, Italy, in 2007.

Since 2010, he has been a Researcher with the Quality of Life Division, Istituto Nazionale di Ricerca Metrologica, Turin. He is currently coordinating the European EMPIR Project 16ENG04 MyRailS. His current research interests include the development and characterization of systems and voltage/current transducers for calibration and power quality measurements on medium voltage grids and on railway supply systems, on the calibration of energy meters for on-board train installation and on the study of ferroresonance phenomena, development of generation, and measurement systems of electromagnetic fields for calibration and dosimetric purposes. 


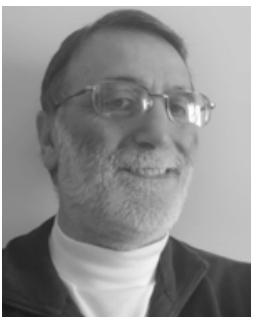

Carmine Landi (M'96-SM'08) was born in Salerno, Italy, in 1955. He received the Laurea degree in electrical engineering from the University of Naples, Naples, Italy, in 1981.

From 1982 to 1992 , he was an Assistant Professor of electrical measurement with the University of Naples “Federico II,'Naples. From 1992 to 1999, he was an Associate Professor of electrical and electronic measurements with the University of L'Aquila, L'Aquila, Italy. Since 1999, he has been a Full Professor with the University of Campania "Luigi Vanvitelli," Aversa, Italy. He has authored more than 200 international papers in real-time measurement apparatus, automated test equipment, highprecision power measurement, and power quality measurement. His current research interests include the setup of digital measurement instrumentation, the automatic testing of electrical machines such as asynchronous motors and power transformers, measurement techniques for the characterization of digital communication devices, and the use of digital signal processors for real-time measurements.

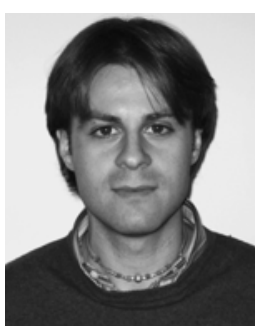

Mario Luiso (S'07-M'08) was born in Naples, Italy, in 1981. He received the Laurea degree (summa cum laude) in electronic engineering and the Ph.D. degree in electrical energy conversion from the University of Campania "Luigi Vanvitelli," Aversa, Italy, in 2005 and 2007, respectively.

$\mathrm{He}$ is currently an Associate Professor with the Department Engineering, University of Campania "Luigi Vanvitelli." He has authored or co-authored more than 150 papers published in books, international scientific journals, and conference proceedings. His current research interests include the development of innovative methods, sensors, and instrumentation for power system measurements, in particular, power quality, calibration of instrument transformers, phasor measurement units, and smart meters.

Dr. Luiso is a Member of the IEEE Instrumentation and Measurement Society.

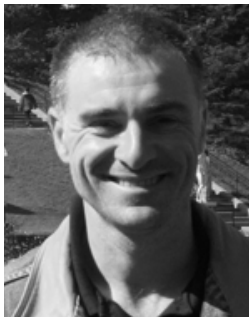

Andrea Mariscotti (M'95-SM'12) received the M.S. degree (cum laude) in electronics engineering and the $\mathrm{Ph} . \mathrm{D}$. in electrical engineering from the University of Genova, Genova, Italy, in 1991 and 1997, respectively.

From 1998 to 2004, he was a Tenure Researcher under different grants with national and international research programs. In 2005, he joined the Electrical Engineering Department, University of Genoa, as an Assistant Professor. He is on sabbatical leave. He has co-founded ASTM, Switzerland, a company active in the electromagnetic and electrical compatibility sector, performing analysis and tests, and manufacturing instruments. His current research interests include EMC applied to industrial, military and transportation systems, modeling and measurement of electromagnetic interference, and its relevance to safety and availability.

Dr. Mariscotti is a Member of the IEEE Instrumentation and Measurement Society and of the Italian Electrical and Electronic Measurement Group (GMEE). He is a Reviewer for IEEE, Elsevier, and Institute of Physics and Springer.

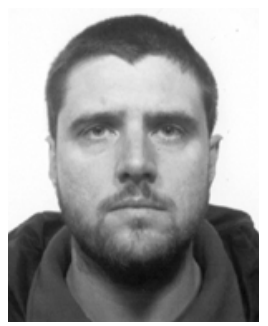

Paolo Emilio Roccato received the M.S. and $\mathrm{Ph} . \mathrm{D}$. degrees in electrical engineering from the Politecnico di Torino, Turin, Italy, in 2005 and 2009, respectively.

Since 2008, he has been with the Istituto Nazionale di Ricerca Metrologica, Turin. His current research interests include the high voltage and high power measurements and reference in testing and calibration. 